\title{
Effectiveness and Adverse Effects of Over-the-Counter Whitening Products on Dental Tissues
}

\author{
Maiara Rodrigues de Freitas, Marynara Mathias de Carvalho, \\ Priscila Christiane Suzy Liporoni, Ana Clara Borges Fort, Rodrigo de Morais e Moura and \\ Rayssa Ferreira Zanatta* \\ Department of Restorative Dentistry, School of Dentistry, University of Taubaté - UNITAU, São Paulo, Brazil
}

\section{OPEN ACCESS}

Edited by:

Vanessa Cavalli,

State University of Campinas, Brazil

Reviewed by:

Matheus Kury,

State University of Campinas, Brazi

Gabriel Nima,

Universidad Cientifica del Sur, Peru

*Correspondence:

Rayssa Ferreira Zanatta rayssa.fzanatta@unitau.br: zanatta.rayssa@gmail.com

Specialty section:

This article was submitted to

Reconstructive Dentistry,

a section of the journal

Frontiers in Dental Medicine

Received: 29 March 2021

Accepted: 24 May 2021

Published: 25 June 2021

Citation:

de Freitas MR, de Carvalho MM, Liporoni PCS, Fort ACB, Moura RM and Zanatta RF (2021) Effectiveness and Adverse Effects

of Over-the-Counter Whitening Products on Dental Tissues.

Front. Dent. Med. 2:687507.

doi: 10.3389/fdmed.2021.687507
The role of bleaching agents (e.g., hydrogen peroxide) in tooth bleaching is quite welldescribed in a few literature studies and considered as the option choice for those desiring brighter teeth, but alternative methods have emerged to fulfill the desire of patients in a faster, easier, and cheaper way. In this context, whitening over-the-counter (OTC) products are available in several vehicles, such as toothpaste, rinses, gums, painton varnishes, and strips, but their effectiveness in terms of bleaching is questioned. This review aimed to describe their mode of action, whitening effectiveness, and harmful effects associated with the indiscriminate use of these products. Dentifrices usually present a combination of abrasives that can induce damage to the tooth surface without evidence of promoting real bleaching. The same was found for rinses, which might present a low $\mathrm{pH}$, with an erosive potential. Charcoal has been included in the composition of these products to improve their whitening effect but there is no evidence supporting it. Regarding strips, they present hydrogen peroxide in a variety of concentrations and are the only OTC products able to promote bleaching. Despite the vehicle, an indication for the use of these products should be made after a careful individual diagnosis of the etiology of the dental staining, considering that most of them seem to be effective only in removing extrinsic stains or preventing their formation over enamel. Also, their indiscriminate use might induce damage and deleterious effects over tooth tissues or gingival tissues. The dentist should be aware of the composition and mode of action of each individual product as they change according to the composition and the vehicle used to recommend the best mode of usage. Still, there is no sound evidence that any of the described OTC products promote a better bleaching effect than the products indicated for a professional.

Keywords: tooth bleaching, bleaching agents, dentifrices, mouthwashes, mouth rinses, over the counter 


\section{INTRODUCTION}

The action of smiling is one of the most basic human expressions, a potent social tool, generally used to express joy and satisfaction, and plays a crucial role in interpersonal relations $(1,2)$. Although being universal in humans, there are a few cross-cultural differences regarding the display and composition of smiles, which, in occidental populations, is idealized by white and aligned teeth, increasing the patient's desire and demands for esthetical dental procedures, often considered as controversial $(3,4)$. The internet, and more recently, social media networks with over 2.6 billion active users can act as a powerful tool to advertise the dental business, treatment options, and digital marketing, besides modulating people's behavior, desires, and consumption habits (5). For example, Instagram, a photo-sharing platform, boosts an upward of 1,050 photos per second (6) with the highest rate of engagement, enabling the users to interact both with their peers and celebrities, creating opportunities for regular exposure to idealized images (5) and smiles.

In this context, professional tooth bleaching is the most popular choice for those desiring brighter teeth, with proven satisfactory aesthetic outcomes and conservative techniques (7-9). The success of bleaching procedures depends mainly on the identification of the color alteration origin, which is usually classified as extrinsic or intrinsic. Extrinsic stains are related to the chromogenic agents' deposition on the enamel surface, such as those from the diet, tobacco consumption, or spontaneous deposition of pigments produced by microorganisms from the biofilm $(10,11)$. Intrinsic stains are related to the pigments inside the tooth tissues caused by medications, such as tetracycline and fluorine; disorders from odontogenesis, such as amelogenesis and dentinogenesis imperfecta; dental trauma; and also local causes, such as pulpal necrosis or hemorrhage, poorly performed endodontic treatment, or root resorption (1113). Once the stain etiology is identified, dentists shall propose an individualized treatment to each patient considering their wishes and expectations, dental condition, and oral health. Usually, tooth bleaching is carried out in the office with more concentrated gels and reduced application time (in-office technique), or at home, under the dentist's supervision, with less concentrated gels and longer application time (at-home technique), or even the association of both techniques $(9,14$, 15). In these protocols, gels containing hydrogen or carbamide peroxides are the most common options $(9,16)$.

In addition, there is a niche in the oral care market comprising toothpaste, rinses, paint-on varnishes, and strips with bleaching or whitening properties, known as over-the-counter (OTC) products. These products are highly available and are presented as an attractive alternative to improve the smile appearance easily and cheaply $(17,18)$. This market has had an estimated growth of $4 \%$ from 2017 to 2021, in the USA, Europe, Asia Pacific, Middle East, and Africa, and is evaluated in more than USD $3 \mathrm{M}$ in this period (19), with more than half of it led only by whitening toothpaste. The success of these products and industry interests lie in the fact that they are considered as cosmetic products. Therefore, they are much less regulated than pharmaceuticals drugs, and in most countries, they usually do not require approval from health regulatory agencies
The inadequate use of these products associated with the population's lack of knowledge about the stain etiology might provide the occurrence of adverse effects, such as excessive wear of dental tissues $(20,21)$ and alteration in enamel or dentin microhardness and roughness (22), mainly due to their high abrasiveness (23). Irritation in the periodontal and soft tissues can occur $(20,24)$ due to their misguided use, and also the ability of most OTC whitening products to promote tooth bleaching is often questioned (25-32). Thus, the aim of this study is to present a brief narrative revision about the effectiveness of OTC dental bleaching products, focusing on their action mode, components, overall whitening efficacy, and side effects on tooth structures. The findings to be discussed are listed below comprising the topics: dentifrices, rinses, paint-on varnishes, whitening strips, and natural products.

\section{METHODS}

An electronic comprehensive search was made through PUBMED, Google Scholar, Scielo, Scopus, and Web of Science considering the following terms: tooth, dental, enamel, bleaching agents, whitening, dentifrices, toothpaste, mouthwashes, rinses, strips, varnish, paint-on varnish, OTC, efficacy, and effectiveness. The terms were searched by using the Boolean operators OR and AND, and the search was performed from July 2020 to February 2021. It included the literature reviews (narrative and systematic), observational and interventional studies (in vitro, in situ, and clinical trials), considering only the ones that were published in English, Portuguese, or Spanish. Case series, case reports, and animal studies were not used as the information in this review. The screening was made by four reviewers (MRF, MMC, ACF, and RMM) independently through titles, abstracts, and full texts. It identified 64 papers from which the type of OTC was evaluated and the main active ingredient test, main mode of action, and analyzed variables were recorded from them (Figures 1, 2).

\section{MAIN FINDINGS}

\section{Dentifrices}

Dentifrices with whitening properties represent more than 50\% of the OTC products with a great variety of components (17). Compared to the regular dentifrices, they generally contain a greater amount of detergents and abrasive systems designed especially to enhance mechanical removal of the biofilm and extrinsic stains $(11,17,28,33)$. In addition, a recent metanalysis of clinical trials concluded that whitening dentifrices were more effective in the stain removal than the regular ones. The authors evaluated 12 studies, which used Lobene, Lobene modified by Macpherson, and the Shaw and Murray indexes to quantify stain removal, and they discussed that the level of evidence was rated as low due to a serious risk of bias and a high heterogeneity of the outcomes (23).

The most common abrasives found in the whitening dentifrices are the following: hydrated silica, calcium carbonate, dicalcium phosphate dihydrate, calcium pyrophosphate, alumina, perlite, nanohydroxyapatite, diamond powder, sodium 
bicarbonate (baking soda), and, more recently, charcoal $(34,35)$. Most of these abrasives are insoluble particles with a higher hardness than the stained pellicle (36). Therefore, their cleaning is effective mainly in extrinsic stains $(23,34)$, having little influence on the intrinsic ones or on the natural color of the teeth. Sodium bicarbonate (baking soda) is one of the most frequently included abrasives in the whitening dentifrices, which is biologically compatible, is capable of acid buffering, and has lower hardness values compared to enamel and dentin (11). Dentifrices having this abrasive presented more clinical effectiveness in the stain removal and whitening effects than the non-baking soda dentifrices $(11,37)$ and the conventional silica-based dentifrices $(38,39)$.

The abrasive potential and the safety of these dentifrices are usually determined by using international measurement methods, such as radiotracer dentin (RDA) and abrasion methods (40). The RDA and REA methods compare the abrasiveness of the dentifrice on the respective dental tissues to a control abrasive material, giving a scale to dentifrices' abrasiveness and rating the values according to its safety. A direct relationship between a dentifrice's stain removal ability and abrasiveness was not always evident (41), and recent data showed that a dentifrice with relatively low abrasiveness was capable of cleaning and promoting a tooth whitening effect $(11,34)$. In addition, it is of great importance that dentifrices, in general, present moderate-to-low abrasiveness in order to prevent enamel surface alterations (such as roughness or microhardness) and, especially, tooth wear $(17,36,42)$. Mainly, the general advice is to avoid whitening dentifrices for the patients with a higher risk of developing erosive tooth wear (ETW) (42), particularly if the dentin is exposed (43), but the literature is very controversial regarding the real effects or correlations between the abrasiveness of the whitening dentifrices and ETW (44-48).

In addition to hardness, the particle type, shape, size, concentration, purity, and hydration levels, detergent types and concentration, or even the dentifrice $\mathrm{pH}$ can modulate the abrasive power of the whitening dentifrices $(35,49-52)$. These factors are usually responsible for the most common side effects reported with the use of whitening dentifrices: tooth sensitivity, soft tissue repercussions, and tooth wear (increase in roughness) (23). So, it is imperative to demand more transparency of the industry regarding the composition of these products, as most of this information is usually not described, making the comprehension in regard to their influence on the enamel/dentin wear and morphological properties very difficult. Still, the description of these components could improve the quality of the studies performed and also the information regarding the risks associated with the self-use or abuse of these products.

Still, being associated with the abrasives, the whitening dentifrices may also contain additional active agents such as sodium citrate, sodium peroxide, and sodium hexametaphosphate that reduce the stain deposition on dental tissues; or sodium pyrophosphate and sodium tripolyphosphate that are anti-calculus agents and reduce the deposition of calcium and magnesium on enamel $(34,49,53)$. Some of these whitening dentifrices can even present hydrogen peroxide as an active ingredient to improve the whitening effect. The effectiveness of highly concentrated hydrogen peroxide gels in tooth whitening is well-established in a few literature studies (7-9), but achieving it using the dentifrices containing lower concentrations is much more challenging, mainly due to a relatively short time exposure comparing to the extrinsic professional dental bleaching. Even though a few studies show that the whitening dentifrices containing low concentrations of hydrogen peroxide (up to 1.5\%) are effective in removing extrinsic stains and promoting tooth color alteration $(25-28,37)$, these results remain controversial $(28,54)$. In addition, a recent metanalysis from Devila et al. (23) corroborates with this, indicating that any overall color change resulting from the whitening dentifrices usage implies the stain removal and should not be confounded with a real bleaching effect.

Finally, a few products can present in their composition a dye called Blue Covarine, which acts based on an optical approach, modifying the visual perception of tooth color by creating more light scattering, shifting the reflected color of the teeth from yellow to blue, thus creating an illusion of greater luminosity (55-57). In vitro findings suggest effective stain removal and whitening using dentifrices with Blue Covarine (36), but a recent clinical trial comparing a dentifrice with this dye to a control one (non-whitening) found no color improvement after a 4week period (58). The authors discussed that the Blue Covarine was able to reduce yellowness ( $b^{*}$ parameter - CIE Lab system) after a 2-week daily treatment, with two daily applications, but this reduction did not remain stable, indicating the need for the constant application of this product to achieve acceptable results. Also, they found out that most of the patients who used both toothpaste were neither satisfied with their whitening effect nor able to notice any improvement in their teeth appearance.

Still, in an attempt to enhance the whitening treatment, patients usually combine the use of whitening dentifrices with professional bleaching treatments that might increase enamel roughness (59). Preliminary results from our group also show that this association increases deleterious effects of enamel and shall not be indicated. A rougher enamel can favor the biofilm deposition and consequently increase not only the risk of caries or periodontal diseases but also the pigment retention from the $\operatorname{diet}(60,61)$.

Therefore, considering the lack of evidence suggesting a real bleaching effect of whitening dentifrices, their use with this purpose shall not be indicated. Patients with smoking habits or an increased risk for the calculus formation and extrinsic staining can be benefited from the use of these products, but its use must be individually evaluated and indicated by a professional based on a clinical examination, caries, and ETW risks, the investigation of habits such as diet and hygiene, and also the composition of these products, in order to avoid the possible damage caused due to incorrect or indiscriminate use.

\section{Whitening Rinses}

In addition to whitening dentifrices, rinses are also an available option in the market as OTC whitening products $(17,62,63)$. Their whitening active agents are: hydrogen peroxide at low concentrations ( $1-4 \%)$, which acts breaking of chromogenic molecules down in teeth substrates; and sodium 


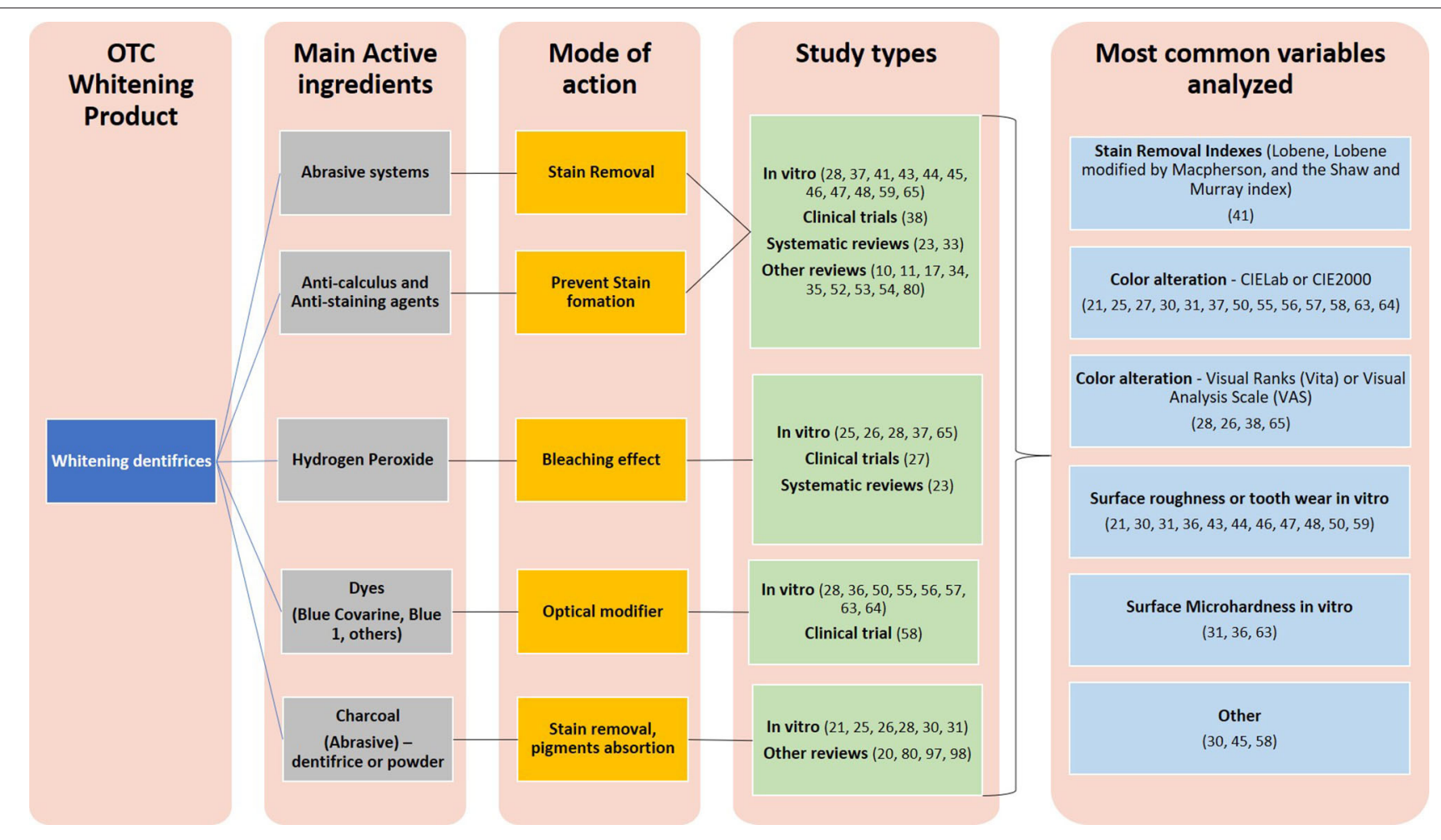

FIGURE 1 | Main findings from the evaluated studies considering whitening dentifrices as OTC.

hexametaphosphate, controlling the extrinsic stain formation $(17,55,64-66)$. Some of them present pyrophosphates in their composition, which have a great affinity to the calcium from hydroxyapatite reducing the ability of extrinsic chromogens to bond with it, therefore acting as a preventive staining agent and not as a whitening one (67). Similar to the dentifrices, these cited active ingredients can be found to be in association in order to enhance their performance.

The main question concerning the effectiveness of whitening rinses lies in their limited penetration into teeth structures when compared to the professional bleaching technique with more concentrated peroxide gels (68). For instance, a 1.5\% hydrogen peroxide mouth rinse was effective in reducing gingivitis and promoting whiter teeth after 6 months of use (69); while the similar color alteration was found between the 1.5 and $2 \%$ hydrogen peroxide rinses used for 12 weeks and the $10 \%$ carbamide peroxide used for 14 days (55). Still, there are reports stating that a $1.5 \%$ hydrogen peroxide rinse could promote some level of dental bleaching, but lower than the $10 \%$ carbamide peroxide $(64,70)$, while no significant bleaching effect was observed by the use of a $4 \%$ hydrogen peroxide whitening rinse on the stained teeth after a 21-day treatment period (71). The use of 1.5 and $2 \%$ hydrogen peroxide rinses could also maintain the whitening outcome of a $10 \%$ carbamide peroxide previously applied following an at-home technique, up to 3 months under staining situations (72). These controversial results can be attributed to the great variations of protocols and the usage of products. Thus, more clinical trials are needed to ensure their effectiveness and the best protocol to use them.

Also, the frequent or abusive use of these products can induce some damages to the dental surface, mainly the ones presenting low $\mathrm{pH}$, which can be erosive $(73,74)$, and cause even greater damage to exposed dentin (75). Lima et al. (66), for example, showed a decrease in the lightness of enamel exposed to a $1.5 \%$ hydrogen peroxide rinse twice a day for 45 days due to the acidic nature of the tested product. This essential information is usually not described in the product and their indiscriminate use by patients, especially those with a high risk of developing erosive wear, might increase the enamel and dentin loss. Still, the continuous use of these rinses associated with tooth brushing can increase the enamel abrasion potential promoted by daily tooth brushing (62). Even so, their inadequate use might also cause teeth sensitivity and gingival irritation (76).

There is a concern regarding the carcinogenic risk between the combination of hydrogen peroxide and alcohol, and also tobacco carcinogen MBA (9,10-dimethyl-1,2-benzanthracene) (77). Even though the low concentration of the peroxide agent in most of the whitening rinses makes them safer to use, with evidence showing no damage in soft tissues and no significant risk of adverse long-term effects (78), clinical evidence is scarce regarding this topic, and there is a recommendation to avoid alcohol and smoking during at-home and self-care bleaching treatments $(77,79)$. 


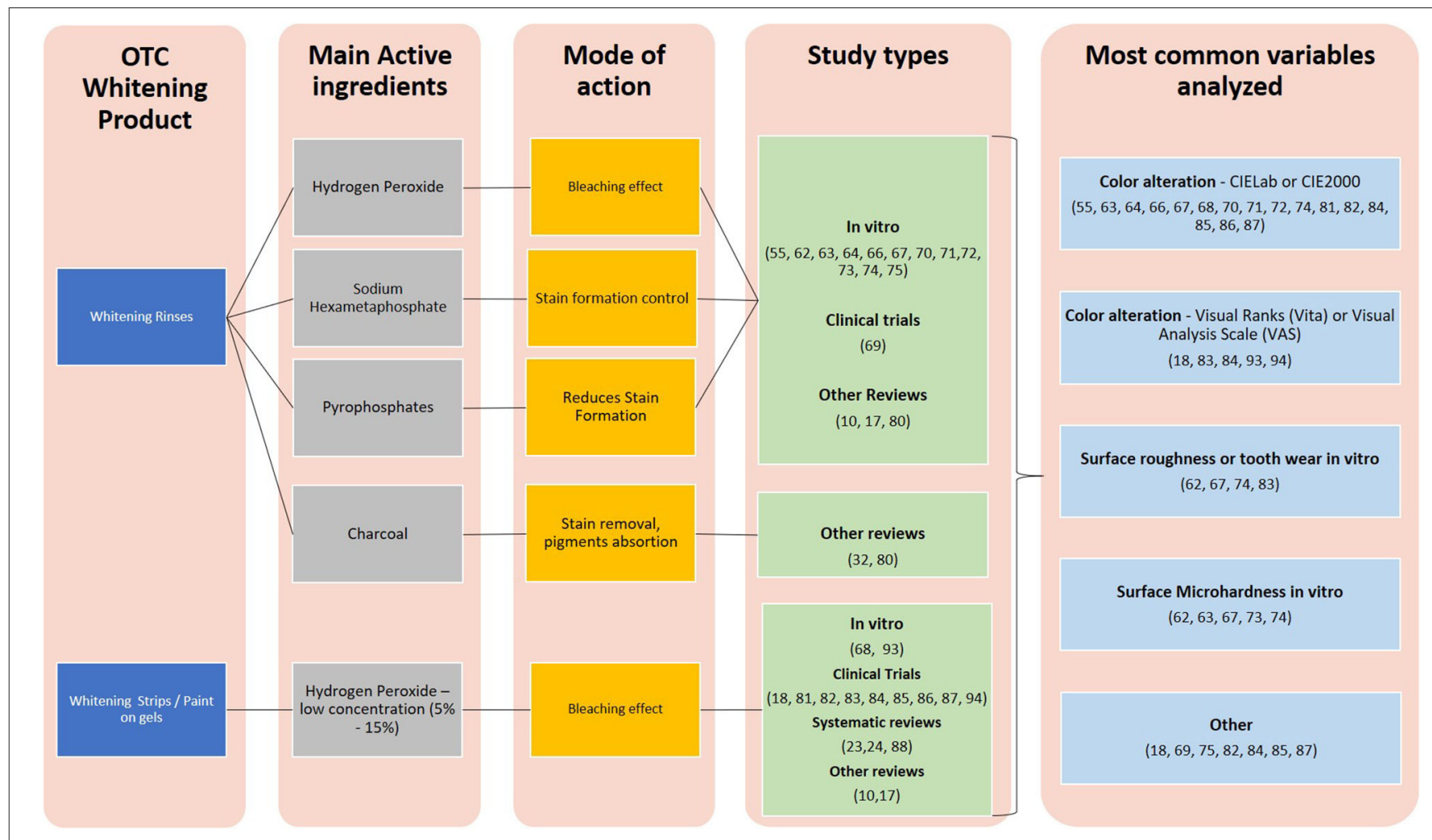

FIGURE 2 | Main findings from the evaluated studies considering whitening rinses and whitening strips (or paint-on gels) as OTC.

\section{Whitening Strips, Chewing Gums, and Paint-On Gels}

Whitening strips consist of plastic holders typically containing $5-15 \%$ hydrogen peroxide, developed with the main idea of avoiding the customized trays used in an at-home dental bleaching technique. They are commercially available in some countries as OTC products and can be applied by the consumer directly to the teeth between 5 and $60 \mathrm{~min}$, once or twice a day, for 14 days -18 months $(17,80)$. Clinical trials show that they are effective and promote comparable results to carbamide peroxide tray treatments (81-84), and a recent meta-analysis concluded, with a moderate level of evidence, that the differences in color change among the dentist's supervised at-home bleaching technique and the use of OTC whitening strips were undetectable by unaided human eyes (24). Whitening strips are the most effective option in the majority of the studies comparing them to other OTC whitening agents (dentifrices, rinses, or painton gels) $(23,80,85,86)$, and these favorable results are mainly attributed to the increased contact time with the enamel and higher hydrogen peroxide concentration. Also, the strips play as a fixed barrier improving the contact with the tooth when compared to paint-on gels $(80,87)$. However, even with these promising results, there is no sound evidence to support their use in the detriment of the American Dental Association (ADA)recommended technique based on the $10 \%$ carbamide peroxide gel applied on customized trays (88).
Also, the indiscriminate use of these strips might lead to tooth sensitivity and gingival irritation (24), and even deleterious effects on dental restorative materials (89). These side effects are easily controlled by a dentist, so a clinical examination of dental and periodontal conditions is of fundamental importance before making use of these strips. Therefore, the concentration and regimen of use shall always be indicated by a dental professional. Still, these strips are commercially available just in some countries as OTC products, while, in other countries, their use is restricted and available only under supervision, as the concentration of peroxide is high.

Chewing gums were introduced as an OTC product claiming to prevent extrinsic staining, by presenting agents such as sodium metaphosphate or hexametaphosphate which have a potentially high affinity to hydroxyapatite and exhibit a stronger binding to the tooth than to a stain (90). Its effectiveness has been tested in clinical trials, showing favorable results in terms of preventing coffee or tea stains (90-92); however, there is no evidence that they can work better than other OTC products or professional bleaching treatments.

Paint-on gels or varnishes are the products containing hydrogen or carbamide peroxide in a wide range of concentrations, incorporated into a suspension that enables them to adhere to enamel without physical barriers (such as trays) and applied via an applicator (brush, pen, cotton buds, etc.) (93). They appeared in the market at the beginning of 
the 2000s as a low-cost alternative to professional bleaching, and since then, they became very popular (17). A clinical study showed that the use of a $6 \%$ hydrogen peroxide gel paint-on system had a significant clinical efficacy whether applied by a dental professional or by a patient (94), but a recent systematic review and metanalysis showed that the effectiveness of these systems is inconclusive in terms of whitening efficacy due to a limited number of available studies (80) and also a great variety of products and protocols tested. Still, it shall be pointed out that these products are applied directly over enamel and could touch the oral mucosa or be swollen by the patient, increasing the risk of harmful effects on the periodontal tissues and gastroesophageal tract.

On the internet is also possible to find other OTC products, such as whitening trays activated by light and a large range of videos teaching how to make rinses or miracle formulas for tooth whitening. Science lacks evidence about their effectiveness and even their safety. Lastly, the availability of these OTC products (paint-on gels, strips, chewing gums, etc.) for a direct consumer depends on the regulations from federal agencies, as their concentration of an active ingredient could be considered high in some countries. Patients shall be oriented about the risks involved in self-medication, self-use, and abuse of these products.

\section{Charcoal Based and Other Natural Products}

Changes in the perception of consumers toward animalfree products, coupled with the growing popularity of environmentally sustainable options, are fueling the demand for naturally derived products (95). This boosted the release of several products called "natural," "detox," "vegan," etc., which are trendy due to the support received from social media and many celebrities around the globe (96). In this context, charcoal-based products appeared in the market promising cleaner and whiter teeth. Although its use in oral health dates from ancient Greece and it is still being used as a tooth cleaning agent in many cultures around the world, there is no evidence that it is efficient in terms of cleaning or preventing caries $(20,21)$. Nowadays, it is possible to find it as a component of whitening dentifrices or a powder to be used as a brushing agent, or a whitening rinse, intended to absorb pigments from the diet or the biofilm $(21,97)$ and, consequently, make them easier to remove. So, its action also lies in the removal of extrinsic stains, and not the intrinsic ones, or even an alteration in the tooth's natural color (32).

Charcoal is an abrasive that can be produced from a variety of carbon-rich materials, including nutshells, coconut shells, bamboo, peat, and wood (97), which works to enhance cleaning as previously explained in the section "Dentifrices." Literature studies are very scarce in respect of the whitening efficacy of these products, with in vitro studies showing no evidence of positive results in terms of color alteration for charcoal-based dentifrices and rinses (20,30-32). Clinical evidence of the effectiveness of these products is still not available. Also, there is a concern regarding the abrasiveness of the charcoal-based dentifrices and potential side effects on the enamel structure, such as an increase in its roughness as shown in a few studies $(30,31,98)$. As described above, for the dentifrices topic, this side effect might impact on the biofilm retention and induce more staining. It is also questioned that, due to the high absorption property of charcoal, it can inactivate fluoride or other active ions inside the charcoal-based toothpaste, reducing its capacity to remineralize dental tissues and caries prevention $(20,21,97)$.

Additionally, there are some coal powders being commercialized for a tooth whitening purpose, with no addition of fluoride at all, which might increase the risk of caries in unadvised consumers. That is why some manufacturers suggest that they should be used before tooth brushing with a regular fluoridated dentifrice, which might be confusing for patients. There is also no control or regulation regarding the abrasiveness of these powders, which depends on the source and the methods used to prepare and grind it. The harmful effects on the enamel surface associated with the constant use of these powders are still controversial, with some evidence suggesting no alteration in the enamel roughness $(20,21)$, while a recent study showed an increase on it (30). Further studies shall be performed to improve the quality of evidence. Also, in vitro studies that test the whitening performance report no effectiveness on the tooth whitening $(21,30)$.

\section{FUTURE PERSPECTIVES AND GENERAL FINDINGS}

In addition to the conventional products previously described, other so-called natural alternatives to hydrogen or carbamide peroxide bleaching agents have been mentioned in the literature studies as a possibility for teeth whitening. Some vegetablederived enzymes, such as papain and bromelain, have been tested in dentifrices, with an intention to help with the degradation of the acquired pellicle (34) and improve stain removal (99). A recent systematic review with a metanalysis evaluated several natural extracts, chlorine dioxide, sodium chloride, sodium bicarbonate, vinegar, etc., and their combination with peroxides, and concluded that, although they could be an alternative to tooth whitening, evidence is still scarce (29). Even so, the authors pointed out that there are a great number of patients with these products, indicating an interest of the industry in studying them and possibly developing new OTC options in the near future (29).

The search for whitening OTC products became popular due to their low cost and easy access. Figures 1, 2 summarize the relevant information presented in this text. The main findings from the evaluated studies show little evidence that whitening dentifrices and rinses promote a real bleaching effect regardless of the presence of charcoal, hence their use with a bleaching purpose shall not be indicated. Patients with a high risk of developing the tooth color alteration from extrinsic sources, such as smoking habits or an increased risk for the calculus formation and extrinsic staining, might benefit from the use of these dentifrices and rinses, but their indication should be made after a careful individual diagnosis of the staining, caries, and ETW risks, the investigation of habits such as diet and hygiene, and also the composition of a product, in order to avoid the possible damage caused due to incorrect or indiscriminate 
use. Still, future studies should consider the evaluation of the whitening effectiveness of these dentifrices or rinses in different regimens, such as once a day, or on alternate days, combined with non-whitening dentifrices, in order to possibly reduce side effects.

\section{CONCLUSIONS}

From the presented OTC products, dentifrices and rinses cannot promote the effective performance of whitening while whitening strips are the most effective ones in terms of tooth color change. The indiscriminate use of whitening OTC products might induce damage and deleterious effects on the tooth or gingival tissues, thus an indication of concentration and treatment duration by a professional shall be considered. There is no sound evidence that any of the described OTC products can promote a better whitening effect than the professional ones, and their indiscriminate use is discouraged. In addition, the dentist should be aware of the composition and mode of action of each individual product as they change according to the composition

\section{REFERENCES}

1. Martin J, Rychlowska M, Wood A, Niedenthal P. Smiles as multipurpose social signals. Trends Cogn Sci. (2017) 21:864-77. doi: 10.1016/j.tics.2017.08.007

2. Wang Z, Mao H, Jessica Li Y, Liu F. Smile big or not? Effects of smile intensity on perceptions of warmth and competence. J Consum Res. (2016) 43:787-805. doi: 10.1093/jcr/ucw062

3. Alani A, Kelleher M, Hemmings K, Saunders M, Hunter M, Barclay S, et al. Balancing the risks and benefits associated with cosmetic dentistry - a joint statement by UK specialist dental societies. Br Dent J. (2015) 218:5438. doi: 10.1038/sj.bdj.2015.345

4. Mehta SB, Banerji S, Aulakh R. Patient assessment: preparing for a predictable aesthetic outcome. Dent Update. (2015) 42:78-86. doi: 10.12968/denu.2015.42.1.78

5. Sampson A, Jeremiah HG, Andiappan M, Newton JT. The effect of viewing idealised smile images versus nature images via social media on immediate facial satisfaction in young adults: a randomised controlled trial. J Orthod. (2020) 47:55-64. doi: 10.1177/1465312519899664

6. Stats I live. Instagram Photos Uploaded in 1 Second. (2021). Available online at: https://www.internetlivestats.com/one-second/ (accessed February 20, 2021).

7. Silva FBD, Chisini LA, Demarco FF, Horta BL, Correa MB. Desire for tooth bleaching and treatment performed in Brazilian adults: findings from a birth cohort. Braz Oral Res. (2018) 32:e12. doi: 10.1590/1807-3107bor-2018.vol32.0012

8. Demarco FF, Conde MC, Ely C, Torre EN, Costa JR, Fernández MR, et al. Preferences on vital and nonvital tooth bleaching: a survey among dentists from a city of southern Brazil. Braz Dent J. (2013) 24:52731. doi: 10.1590/0103-6440201302152

9. de Geus JL, Wambier LM, Kossatz S, Loguercio AD, Reis A. At-home vs inoffice bleaching: a systematic review and meta-analysis. Oper Dent. (2016) 41:341-56. doi: 10.2341/15-287-LIT

10. Carey CM. Tooth whitening: what we now know. J Evid Based Dent Pract. (2014) 14:70-6. doi: 10.1016/j.jebdp.2014.02.006

11. Li Y. Stain removal and whitening by baking soda dentifrice. J Am Dent Assoc. (2017) 148:S20-6. doi: 10.1016/j.adaj.2017.09.006

12. Plotino G, Buono L, Grande NM, Pameijer CH, Somma F. Nonvital tooth bleaching: a review of the literature and clinical procedures. J Endod. (2008) 34:394-407. doi: 10.1016/j.joen.2007.12.020

13. Rodríguez-Martínez J, Valiente M, Sánchez-Martín M. Tooth whitening: from the established treatments to novel approaches to prevent side effects. J Esthet Restor Dent. (2019) 31:431-40. doi: 10.1111/jerd.12519 and the vehicle use, in order to recommend the best mode of usage.

\section{AUTHOR CONTRIBUTIONS}

MF and MC collected the data and wrote the initial draft of the manuscript. PL, AF, and RM contributed to the data collection and critically reviewed the draft. RZ designed and supervised the study and the editing process of the manuscript. All authors contributed to the article and approved the submitted version.

\section{FUNDING}

This research was supported by PIBIC Unitau (Grant Number: 0172/2020-ODO).

\section{ACKNOWLEDGMENTS}

The authors would like to thank Jônatas Owsiany de Souza for helping to revise the English version of this manuscript.

14. Joiner A, Luo W. Tooth colour and whiteness: a review. J Dent. (2017) 67S:S3-10. doi: 10.1016/j.jdent.2017.09.006

15. Borges AB, Zanatta RF, Barros AC, Silva LC, Pucci CR, Torres CR. Effect of hydrogen peroxide concentration on enamel color and microhardness. Oper Dent. (2015) 40:96-101. doi: 10.2341/13-371-L

16. Kwon SR, Wertz PW. Review of the mechanism of tooth whitening. J Esthet Restor Dent. (2015) 27:240-57. doi: 10.1111/jerd.12152

17. Demarco FF, Meireles SS, Masotti AS. Over-thecounter whitening agents: a concise review. Braz Oral Res. (2009) 23:64-70. doi: 10.1590/S1806-832420090005 00010

18. Auschill TM, Hellwig E, Schmidale S, Sculean A, Arweiler NB. Efficacy, side-effects and patients' acceptance of different bleaching techniques (OTC, in-office, at-home). Oper Dent. (2005) 30:156-63.

19. Businesswire. Teeth Whitening Market. (2020). Available online at: https:// www.businesswire.com/news/home/20200210005481/en/Teeth-WhiteningMarket-2020-2024Rising-Demand-for-Cosmetic-Dentistry-to-BoostGrowth-Technavio (accessed February 20, 2020).

20. Brooks JK, Bashirelahi N, Reynolds MA. Charcoal and charcoal-based dentifrices: a literature review. J Am Dent Assoc. (2017) 148:66170. doi: 10.1016/j.adaj.2017.05.001

21. Franco MC, Uehara J, Meroni BM, Zuttion GS, Cenci MS. The effect of a charcoal-based powder for enamel dental bleaching. Oper Dent. (2020) 45:618-23. doi: 10.2341/19-122-L

22. Barbieri GM, Mota EG, Rodrigues-Junior SA, Burnett LH Jr. Effect of whitening dentifrices on the surface roughness of commercial composites. $J$ Esthet Restor Dent. (2011) 23:338-45. doi: 10.1111/j.1708-8240.2011.00426.x

23. Devila A, Lasta R, Zanella L, Agnol MD, Rodrigues-Junior SA. Efficacy and adverse effects of whitening dentifrices compared with other products: a systematic review and meta-analysis. Oper Dent. (2020) 45:E7790. doi: 10.2341/18-298-L

24. da Rosa G, Maran BM, Schmitt VL, Loguercio AD, Reis A, Naufel FS. Effectiveness of whitening strips use compared with supervised dental bleaching: a systematic review and meta-analysis. Oper Dent. (2020) 45:E289307. doi: 10.2341/19-160-L

25. Torres VS, Lima MJP, Valdrighi HC, Campos EJ, Santamaria M Jr. Whitening dentifrices effect on enamel with orthodontic braces after simulated brushing. Eur J Dent. (2020) 14:13-8. doi: 10.1055/s-0039-3403474

26. Kakar A, Rustogi K, Zhang YP, Petrone ME, DeVizio W, Proskin HM. A clinical investigation of the tooth whitening efficacy of a new hydrogen peroxide-containing dentifrice. J Clin Dent. (2004) 15:41-5. 
27. Kim HJ, Jang JH, Choi D, Kim J, Shim JH, Kim DS. Bleaching toothpaste with two different concentrations of hydrogen peroxide: a randomized double-blinded clinical trial. J Dent. (2020) 103:103508. doi: 10.1016/j.jdent.2020.103508

28. Vaz VTP, Jubilato DP, Oliveira MRM, Bortolatto JF, Floros MC, Dantas AAR, et al. Whitening toothpaste containing activated charcoal, blue covarine, hydrogen peroxide or microbeads: which one is the most effective? J Appl Oral Sci. (2019) 27:e20180051. doi: 10.1590/1678-7757-2018-0051

29. Ribeiro JS, de Oliveira da Rosa WL, da Silva AF, Piva E, Lund RG. Efficacy of natural, peroxide-free tooth-bleaching agents: a systematic review, meta-analysis, and technological prospecting. Phyther Res. (2020) 34:106070. doi: $10.1002 /$ ptr.6590

30. Palandi SDS, Kury M, Picolo MZD, Coelho CSS, Cavalli V. Effects of activated charcoal powder combined with toothpastes on enamel color change and surface properties. J Esthet Restor Dent. (2020) 32:78390. doi: 10.1111/jerd.12646

31. Koc Vural U, Bagdatli Z, Yilmaz AE, Yalçin Çakir F, Altundaşar E, Gurgan S. Effects of charcoal-based whitening toothpastes on human enamel in terms of color, surface roughness, and microhardness: an in vitro study. Clin Oral Investig. (2021). doi: 10.1007/s00784-021-03903-x [Epub Ahead of Print].

32. Brooks JK, Bashirelahi N, Hsia RC, Reynolds MA. Charcoalbased mouthwashes : a literature review. Br Dent J. (2020) 228:290-4. doi: 10.1038/s41415-020-1265-8

33. Soeteman GD, Valkenburg C, Van der Weijden GA, Van Loveren C, Bakker E, Slot DE. Whitening dentifrice and tooth surface discolorationa systematic review and meta-analysis. Int J Dent Hyg. (2018) 16:2435. doi: 10.1111/idh.12289

34. Joiner A. Whitening toothpastes: a review of the literature. J Dent. (2010) 38:e17-24. doi: 10.1016/j.jdent.2010.05.017

35. Hara AT, Turssi CP. Baking soda as an abrasive in toothpastes. J Am Dent Assoc. (2017) 148:S27-33. doi: 10.1016/j.adaj.2017.09.007

36. Joiner A, Philpotts CJ, Ashcroft AT, Laucello $\mathrm{M}$, Salvaderi A. In vitro cleaning, abrasion and fluoride efficacy of a new silica based whitening toothpaste containing blue covarine. J Dent. (2008) 36:327. doi: 10.1016/j.jdent.2008.02.003

37. Kleber $\mathrm{C}$, Putt $\mathrm{M}$, Nelson B. In vitro tooth whitening by a sodium bicarbonate/peroxide dentifrice. J Clin Dent. (1998) 9:16-21.

38. Koertge TE, Brooks CN, Sarbin AG, Powers D, Gunsolley JC. A longitudinal comparison of tooth whitening resulting from dentifrice use. J Clin Dent. (1998) 9:67-71.

39. Li Y. Tooth color measurement using chroma meter: techniques, advantages, and disadvantages. J Esthet Restor Dent. (2003) 15:33-41. doi: 10.1111/j.1708-8240.2003.tb00316.x

40. Hefferren JJ. A laboratory method for assessment of dentrifrice abrasivity. $J$ Dent Res. (1976) 55:563-73. doi: 10.1177/00220345760550040301

41. Schemehorn BR, Moore MH, Putt MS. Abrasion, polishing, and stain removal characteristics of various commercial dentifrices in vitro. J Clin Dent. (2011) 22:11-8.

42. Magalhães AC, Wiegand A, Buzalaf MA. Use of dentifrices to prevent erosive tooth wear: harmful or helpful? Braz Oral Res. (2014) 28:16. doi: 10.1590/S1806-83242013005000035

43. Vertuan M, de Souza BM, Machado PF, Mosquim V, Magalhães AC. The effect of commercial whitening toothpastes on erosive dentin wear in vitro. Arch Oral Biol. (2020) 109:104580. doi: 10.1016/j.archoralbio.2019.104580

44. Simões ACCD, Dionizio A, Câmara JVF, Sabino-Arias IT, Levy FM, Ventura TMO, et al. Do commercial whitening dentifrices increase enamel erosive tooth wear? J Appl Oral Sci. (2020) 27:e20190163. doi: 10.1590/1678-7757-2019-0163

45. Nakamura M, Kitasako Y, Nakashima S, Sadr A, Tagami J. Impact of toothpaste on abrasion of sound and eroded enamel: an in vitro white light interferometer study. Am J Dent. (2015) 28:268-72.

46. Joiner A, Collins LZ, Cox TF, Pickles MJ, Weader E, Liscombe C, et al. The measurement of enamel and dentine abrasion by tooth whitening products using an in situ model. Int Dent J. (2005) 55:1946. doi: 10.1111/j.1875-595X.2005.tb00059.x

47. Lima LC, Viana ÍEL, Paz SLPD, Bezerra SJC, João-Souza SH, Carvalho TS, et al. Role of desensitizing/whitening dentifrices in enamel wear. J Dent. (2020) 99:103390. doi: 10.1016/j.jdent.2020.103390
48. Mosquim V, Martines Souza B, Foratori Junior GA, Wang L, Magalhães AC. The abrasive effect of commercial whitening toothpastes on eroded enamel. Am J Dent. (2017) 30:142-6.

49. Joiner A. The cleaning of teeth. In: Handbook for Cleaning/Decontamination of Surfaces. Amsterdam: Elsevier (2007). p. 371-405.

50. Silva EMD, Maia JNDSMD, Mitraud CG, Russo JDES, Poskus LT, Guimarães JGA. Can whitening toothpastes maintain the optical stability of enamel over time? J Appl Oral Sci. (2018) 26:288-92. doi: 10.1590/1678-7757-2016-0460

51. Lippert F, Arrageg MA, Eckert GJ, Hara AT. Interaction between toothpaste abrasivity and toothbrush filament stiffness on the development of erosive/abrasive lesions in vitro. Int Dent J. (2017) 67:344-50. doi: 10.1111/idj.12305

52. González-Cabezas C, Hara AT, Hefferren J, Lippert F. Abrasivity testing of dentifrices - challenges and current state of the art. Monogr Oral Sci. (2013) 23:100-7. doi: 10.1159/000350476

53. Baig A, He T, Buisson J, Sagel L, Suszcynsky-Meister E, White DJ. Extrinsic whitening effects of sodium hexametaphosphate-a review including a dentifrice with stabilized stannous fluoride. Compend Contin Educ Dent. (2005) 26(9 Suppl 1):47-53.

54. Alshara S, Lippert F, Eckert GJ, Hara AT. Effectiveness and mode of action of whitening dentifrices on enamel extrinsic stains. Clin Oral Investig. (2014) 18:563-9. doi: 10.1007/s00784-013-0981-8

55. Torres CR, Perote LC, Gutierrez NC, Pucci CR, Borges AB. Efficacy of mouth rinses and toothpaste on tooth whitening. Oper Dent. (2013) 38:5762. doi: 10.2341/11-360-L

56. Dantas AA, Bortolatto JF, Roncolato Á, Merchan H, Floros MC, Kuga MC, et al. Can a bleaching toothpaste containing blue Covarine demonstrate the same bleaching as conventional techniques? An in vitro, randomized and blinded study. J Appl Oral Sci. (2015) 23:609-13. doi: 10.1590/1678-7757201 50268

57. Bortolatto JF, Dantas AA, Roncolato Á, Merchan H, Floros MC, Kuga MC, et al. Does a toothpaste containing blue covarine have any effect on bleached teeth? An in vitro, randomized and blinded study. Braz Oral Res. (2016) 30:1-7. doi: 10.1590/1807-3107BOR-2016.vol30.0033

58. Meireles SS, de Sousa JP, Lins RBE, Sampaio FC. Efficacy of whitening toothpaste containing blue covarine: a double-blind controlled randomized clinical trial. J Esthet Restor Dent. (2021) 33:341-50. doi: 10.1111/jerd.12605

59. Özkan P, Kansu G, Özak ST, Kurtulmuş-Yilmaz S, Kansu P. Effect of bleaching agents and whitening dentifrices on the surface roughness of human teeth enamel. Acta Odontol Scand. (2013) 71:488-97. doi: 10.3109/00016357.2012.696691

60. Quirynen M, Bollen CM. The influence of surface roughness and surface-free energy on supra- and subgingival plaque formation in man. A review of the literature. J Clin Periodontol. (1995) 22:1-14. doi: 10.1111/j.1600-051X.1995.tb01765.x

61. Watts DC, Addy M. Tooth discolouration and staining: a review of the literature. Br Dent J. (2001) 190:309-16. doi: 10.1038/sj.bdj.4800959a

62. Torres CRG, Bonício GC, Crastechini É, Mailart MC, Borges AB. Effect of whitening mouthrinses on enamel toothbrush abrasion. Am J Dent. (2018) 31:285-9.

63. Jurema AL, Claudino ES, Torres CR, Bresciani E, Caneppele TM. Effect of over-the-counter whitening products associated or not with $10 \%$ carbamide peroxide on color change and microhardness: in vitro study. J Contemp Dent Pract. (2018) 19:359-66. doi: 10.5005/jp-journals-10024-2267

64. Karadas M. Efficacy of whitening oral rinses and dentifrices on color stability of bleached teeth. Acta Biomater Odontol Scand. (2015) 1:2934. doi: 10.3109/23337931.2015.1039537

65. Soares CN, Amaral FL, Mesquita MF, Franca FM, Basting RT, Turssi CP. Toothpastes containing abrasive and chemical whitening agents: efficacy in reducing extrinsic dental staining. Gen Dent. (2015) 63:e24-8.

66. Lima FG, Rotta TA, Penso S, Meireles SS, Demarco FF. In vitro evaluation of the whitening effect of mouth rinses containing hydrogen peroxide. Braz Oral Res. (2012) 26:269-74. doi: 10.1590/S1806-832420120003 00014

67. Vieira-Junior WF, Ferraz LN, Giorgi M, Ambrosano G, Aguiar F, Lima D. Effect of mouth rinse treatments on bleached enamel properties, surface morphology, and tooth color. Oper Dent. (2019) 44:178-87. doi: 10.2341/17-250-L 
68. Dietschi D, Benbachir N, Krejci I. In vitro colorimetric evaluation of the efficacy of home bleaching and over-the-counter bleaching products. Quintessence Int. (2010) 41:505-16.

69. Hasturk H, Nunn M, Warbington M, Van Dyke TE. Efficacy of a fluoridated hydrogen peroxide-based mouthrinse for the treatment of gingivitis: a randomized clinical trial. J Periodontol. (2004) 75:5765. doi: 10.1902/jop.2004.75.1.57

70. Jaime IM, França FM, Basting RT, Turssi CP, Amaral FL. Efficacy of hydrogen-peroxide-based mouthwash in altering enamel color. Am J Dent. (2014) 27:47-50.

71. Potgieter E, Grobler SR. Whitening efficacy of three over-the-counter oral rinses. SADJ J South African Dent Assoc. (2011) 66:128-31.

72. Oliveira J, Sarlo RS, Bresciani E, Caneppele T. Whitening efficacy of whitening mouth rinses used alone or in conjunction with carbamide peroxide home whitening. Oper Dent. (2017) 42:319-26. doi: 10.2341/15-361-L

73. Potgieter E, Osman Y, Grobler SR. The effect of three whitening oral rinses on enamel micro-hardness. SADJ J South African Dent Assoc. (2014) 69:152, 154-6.

74. Favaro JC, Geha O, Guiraldo RD, Lopes MB, Aranha AMF, Berger SB. Evaluation of the effects of whitening mouth rinses combined with conventional tooth bleaching treatments. Restor Dent Endod. (2019) 44:e6. doi: 10.5395/rde.2019.44.e6

75. Lima JP, Melo MA, Passos VF, Braga CL, Rodrigues LK, Santiago SL. Dentin erosion by whitening mouthwash associated to toothbrushing abrasion: a focus variation 3D scanning microscopy study. Microsc Res Tech. (2013) 76:904-8. doi: $10.1002 /$ jemt.22246

76. Goldberg M, Grootveld M, Lynch E. Undesirable and adverse effects of tooth-whitening products: a review. Clin Oral Investig. (2009) 14:110. doi: 10.1007/s00784-009-0302-4

77. Consolaro A. Mouthwashes with hydrogen peroxide are carcinogenic, but are freely indicated on the Internet: warn your patients! Dent Press J Orthod. (2013) 18:5-12. doi: 10.1590/S2176-94512013000600002

78. Walsh LJ. Safety issues relating to the use of hydrogen peroxide in dentistry. Aust Dent J. (2000) 45:257-69; quiz: 289. doi: 10.1111/j.1834-7819.2000.tb00261.x

79. Naik S, Tredwin CJ, Scully C. Hydrogen peroxide tooth-whitening (bleaching): review of safety in relation to possible carcinogenesis. Oral Oncol. (2006) 42:668-74. doi: 10.1016/j.oraloncology.2005.10.020

80. Naidu AS, Bennani V, Brunton JMAP, Brunton P. Over-the-counter tooth whitening agents: a review of literature. Braz Dent J. (2020) 31:22135. doi: 10.1590/0103-6440202003227

81. Ferrari M, Cagidiaco MC, Monticelli F, Kugel G, Barker ML, Gerlach RW. Daytime use of a custom bleaching tray or whitening strips: initial and sustained color improvement. Am J Dent. (2009) 22:114.

82. Hannig C, Lindner D, Attin T. Efficacy and tolerability of two home bleaching systems having different peroxide delivery. Clin Oral Investig. (2007) 11:3219. doi: 10.1007/s00784-007-0128-x

83. Auschill TM, Schneider-Del Savio T, Hellwig E, Arweiler NB. Randomized clinical trial of the efficacy, tolerability, and long-term color stability of two bleaching techniques: 18-month follow-up. Quintessence Int. (2012) 43:683-94.

84. da Costa JB, McPharlin R, Hilton T, Ferracane JI, Wang M. Comparison of two at-home whitening products of similar peroxide concentration and different delivery methods. Oper Dent. (2012) 37:333-9. doi: 10.2341/11053-C

85. Xu X, Zhu L, Tang Y, Wang Y, Zhang K, Li S, et al. Randomized clinical trial comparing whitening strips, paint-on gel and negative control. Am J Dent. (2007) 20:28A-31A.
86. Gerlach RW, Barker ML. Clinical response of three direct-to-consumer whitening products: strips, paint-on gel, and dentifrice. Compend Contin Educ Dent. (2003) 24:458, 461-4, 466 passim.

87. Bizhang M, Müller M, Phark JH, Barker ML, Gerlach RW. Clinical trial of long-term color stability of hydrogen peroxide strips and sodium percarbonate film. Am J Dent. (2007) 20:23A-7A.

88. Serraglio CR, Zanella L, Dalla-Vecchia KB, Rodrigues-Junior SA. Efficacy and safety of over-the-counter whitening strips as compared to home-whitening with $10 \%$ carbamide peroxide gelsystematic review of RCTs and metanalysis. Clin Oral Investig. (2016) 20:1-14. doi: 10.1007/s00784-015-1547-8

89. Takesh T, Sargsyan A, Lee M, Anbarani A, Ho J, Wilder-Smith P. Evaluating the whitening and microstructural effects of a novel whitening strip on porcelain and composite dental materials. Dentistry. (2017) 7:448. doi: 10.4172/2161-1122.1000448

90. Makino S, Kawamoto C, Ikeda T, Doi T, Narise A, Tanaka T, et al. Whitening efficacy of chewing gum containing sodium metaphosphate on coffee stain: placebo-controlled, double-blind in situ examination. Oper Dent. (2019) 44:469-75. doi: 10.2341/17-385-C

91. Milleman JL, Milleman KR, Kleber CJ, Proskin HM, Dodds M, Kelley M, et al. Crossover clinical investigation of a whitening chewing gum for inhibiting dental stain formation in conjunction with tooth brushing. J Clin Dent. (2014) 25:37-42.

92. Porciani PF, Grandini S, Perra C, Grandini R. Whitening effect by stain inhibition from a chewing gum with sodium hexametaphosphate in a controlled twelve-week single-blind trial. J Clin Dent. (2006) 17:14-6.

93. Kishta-Derani M, Neiva G, Yaman P, Dennison D. In vitro evaluation of tooth-color change using four paint-on tooth whiteners. Oper Dent. (2007) 32:394-8. doi: 10.2341/06-117

94. Oteo Calatayud J, Mateos de la Varga P, Oteo Calatayud C, Calvo Box MJ. Comparative clinical study of two tooth bleaching protocols with $6 \%$ hydrogen peroxide. Int J Dent. (2009) 2009:928306. doi: 10.1155/2009/ 928306

95. Amberg N, Fogarassy C. Green consumer behavior in the cosmetics market. Resources. (2019) 8:137. doi: 10.3390/resources 80 30137

96. Brazilian Industry of Cosmetics. Caderno de Tendencias 2019-2020 Sebrae. (2020). Available online at: https://www.sebrae.com.br/Sebrae/PortalSebrae/ Anexos/CADERNODETENDENCIAS2019-2020SebraeAbihpecvsfinal.pdf

97. Greenwall LH, Greenwall-Cohen J, Wilson NHF. Charcoal-containing dentifrices. Br Dent J. (2019) 226:697-700. doi: 10.1038/s41415-019-0232-8

98. Pertiwi UI, Eriwati YK, Irawan B. Surface changes of enamel after brushing with charcoal toothpaste. J Phys. (2017) 884:012002.

99. Kalyana P, Shashidhar A, Meghashyam B, SreeVidya K, Sweta S containing papain and Bromelain extracts - an in vitro study. Int J Dent Hyg. (2011) 9:229-33. doi: 10.1111/j.1601-5037.2010.00473.x

Conflict of Interest: The authors declare that the research was conducted in the absence of any commercial or financial relationships that could be construed as a potential conflict of interest.

Copyright (C) 2021 de Freitas, de Carvalho, Liporoni, Fort, Moura and Zanatta. This is an open-access article distributed under the terms of the Creative Commons Attribution License (CC BY). The use, distribution or reproduction in other forums is permitted, provided the original author(s) and the copyright owner(s) are credited and that the original publication in this journal is cited, in accordance with accepted academic practice. No use, distribution or reproduction is permitted which does not comply with these terms. 